\title{
ENSINO DE ARTE E EDUCAÇÃO PROFISSIONAL FEMININA: UM ESTUDO DE CASO SOBRE A ESCOLA PROFISSIONAL FEMININA DE SÃO PAULO
}

Carolina Marielli Barreto ${ }^{1}$

Orientadora: Rejane G. Coutinho

\section{Resumo}

A presente pesquisa tem como objeto o estudo do desenvolvimento do ensino de arte voltado para as artes aplicadas a indústria como forma de profissionalização feminina dentro da Escola Profissional Feminina de São Paulo, fazendo-se necessário um estudo das relações que se estabeleceram entre questões relativas à educação de gênero, da arte aplicada à industria e os ofícios manuais, situando a experiência no cenário educacional brasileiro e conceituando o que significava a profissionalização feminina.

O estudo toma como fundamentação as pesquisas sobre a história do ensino de arte tendo como fonte teórica as idéias difundidas por Ana Mae no que se refere a revisão da história como subsídio para uma compreensão mais completa das origens das práticas e dos preconceitos pedagógicos ainda existentes no campo do ensino de arte.

Palavras-chave: história do ensino de arte no brasil, educação feminina, ensino de arte, artes aplicadas

\begin{abstract}
The present research has as object the study of the development of the education of art directed to the arts and crafts as form of feminine professionalization inside of the Escola Profissional Feminina de São Paulo. Is necessary a study of the relations of the education of sort, the art applied to the manual industria and crafts, pointing out the experience in the educational scene Brazilian and appraising what it meant the professionalization feminine.

The study the ideas spread out for Ana Mae Barbosa as for revision of history take as recital the research on the history of the art education having as theoretical source as subsidy for a more complete understanding of the origins of the practical ones and still existing the pedagogical preconceptions in the field of the art education.
\end{abstract}

Keywords: history of the education of art in Brazil, feminine education, education of art, arts and crafts

O presente trabalho busca a compreensão do ideário de ensino de arte presente nos pressupostos que fomentaram a criação, em 1911, da Escola Profissional Feminina de São Paulo.

A criação da Escola Profissional Feminina de São Paulo foi um projeto e uma experiência pioneira do ponto de vista das políticas educacionais públicas.

Criada em 1911, a instituição foi destinada ao público feminino, voltado ao ensino das artes tidas como femininas aplicadas à indústria. A finalidade era de preparar mão de obra qualificada e apta a crescente industrialização que se processava em São Paulo.

1 Mestrado em Artes - Instituto de Artes da Unesp 
O interesse em abordar a Escola Profissional Feminina como objeto de um estudo de caso, está na riqueza de questões que sua implantação traz, em relação a finalidade do ensino da arte dentro do contexto específico da profissionalização feminina. A Escola Profissional Feminina de São Paulo se apresenta como um fio condutor de uma rede de temas e discussões que inter-relacionam questões ligadas à arte, à técnica, à educação de gênero e ao trabalho.

A respeito da proposta de criação da Escola Profissional Feminina, juntamente com a Escola Profissional Masculina, ambas foram organizadas e regulamentadas pelo Governo Estadual de São Paulo como projeto educacional voltado para o ensino profissionalizante com ênfase no aprendizado das artes aplicadas à industria.

Sobre os objetivos de tais instituições dentro do cenário educacional da época, Carmen Moraes afirma que o Governo Estadual visava contribuir para a qualificação de mão de obra, atendendo às necessidades da crescente industrialização de São Paulo, principalmente do setor fabril, tornando de tal modo o operariado nacional competitivo. Estas escolas eram destinadas ao "ensino das profissões mais adequadas ao meio industrial", o ensino das "artes industriais" para o sexo masculino e de "prendas manuais" para o sexo feminino (Moraes, 2002: 17-19).

As escolas profissionais eram dirigidas aos filhos dos trabalhadores que deveriam seguir a profissão dos pais. O objetivo era educar as crianças e jovens do meio fabril com base na ordem, na disciplina, na devoção ao trabalho e cultivar o elevado espírito patriótico.

Num ambiente conturbado pelas inovações tecnológicas da época, pela chegada de imigrantes de várias procedências e sob as mais diversas influenciais de caráter sóciopolítico, o recurso era a preparação da força de trabalho com intuito de combater as tendências libertárias e anarquistas presentes no trabalhador imigrante.

Cabe acrescentar que ambas as escolas foram instaladas no bairro do Brás, que na época, vivia um período de intensa atividade fabril e comercial, com grande concentração de operários e imigrantes.

O ensino da arte, mas propriamente dito o ensino do desenho assumiu papel relevante na educação para o trabalho, seja ele como objeto disciplinador, ou como forma de aperfeiçoar a mão-de-obra e cultivar o espírito do trabalhador. Esse ensino era diferentemente tratado de acordo com o sexo, utilizando-se da fala de Michelle Perrot, "Ao homem, a madeira e os metais. À mulher, a família e os tecidos" (apud. Nadai, 1991: 24). Tal discurso persistiu no ensino da disciplina "Trabalhos Manuais" até os anos sessenta do século XX.

Para que se compreenda a importância da instituição se faz necessária uma exposição sobre os padrões de ensino voltado as mulheres e o significado que assume o termo "profissionalização feminina" para a época. Nesse particular, no entanto, seria preciso atentar ainda para as diferenças em função das diferenças sociais.

Segundo aponta Jefrey Needel (1997: 75) o ensino das moças compreendia uma lista de refinamentos com o intuito de melhorar sua reputação aos olhos de um possível noivo e respectiva família. Nesse contexto, a arte se apresenta como ornamentação ao espírito feminino, considerado completar. Elza Nadai (1991: 24). aponta ainda uma distinção no que se refere ao ensino dos Trabalhos de Agulha voltado ao ensino sobretudo do bordado para as moças da elite enquanto que a arte da costura era então destinada as meninas pobres. 
Segundo Nadai as atividades de costura, estavam relegadas a um plano considerado inferior e, portanto, eram destinadas às mulheres destituídas de dinheiro, prestígio ou poder, componentes da "pobreza envergonhada". Um número significativo de mulheres tendo perdido seus maridos ou sua herança, sobreviviam de seu ofício de costurar e este ficou restrito ao universo do trabalho manual, transformando-o em atividade lucrativa e comercial (1991: 22-26).

Cabe ainda ressaltar que segundo Nadai, a noção de trabalho não se relacionava nem ao exercício de alguma atividade remunerada e nem à escolha de qualquer campo profissional. Mesmo a profissionalização "aceita" pelos padrões sociais - o magistério - não o era para a mulher de origem burguesa e sim para aquelas provenientes de setores empobrecidos da burguesia ou originários das camadas médias.

Este desvalor do trabalho manual, segundo Cunha, encontra sua origem na intensificação do emprego de escravos no mundo ocidental como fruto de uma reorientação do pensamento grego a partir do século IV a.C. determinado por elementos econômicos e políticos. Esta herança cultural teve influência marcante no processo de colonização brasileiro, as relações escravistas de produção impediram o desenvolvimento das atividades artesanais e manufatureiras do homem livre, atribuindo o trabalho manual a "coisa de escravo". Mesmo as camadas mais pobres ou mestiças se afastavam dessas atividades manuais como uma forma de diferenciação social (Cunha, 2000a:7)

O ensino de ofícios manuais era então imposto como aprendizagem compulsória àqueles que eram incapazes de resistir. Segundo Jorge Nagle, o ensino técnico-profissional desde o período colonial até o início do século XX foi organizado com o objetivo expresso de atender às "classes populares", às "classes pobres", aos "meninos desvalidos", “órfãos", "abandonados", "desfavorecidos da fortuna", figurando mais como um plano assistencial aos "necessitados da misericórdia pública" do que um programa, educacional, sendo a regeneração pelo trabalho muitas vezes, explicitamente proposta (2001: 212).

Sob os aspectos apresentados por Jorge Nagle a respeito do ensino de ofícios manuais no final período Imperial, em São Paulo, o governo mantinha duas casas de recolhimento e educação de crianças órfãs e abandonadas ambas criadas como obra de assistência social aos "desfavorecidos da sorte" sendo elas: O Instituto de Educandos Artífices, para meninos, e o Seminário da Glória, para meninas, orfanato dirigido pelas Irmãs de São José. Segundo Ivan Manuel a função do Seminário da Glória era de prepar as meninas orfãs para exercer os serviços de domésticas ensinando a elas além do catecismo, gramática portuguesa, história sagrada, aritmética e geografia a costura, pontos de meia e todos os outros trabalhos de agulha; cozinhar e, em geral, todas as "prendas domésticas próprias da condição de órfãs" (Manuel,1997: 74-75).

Nesse sentido a Escola Profissional Feminina voltada para o ensino de "Prendas Manuais" faz um contraponto ao modelo de educação feminina eminentemente propedêutica difundido pela Escola Normal da Praça (Reis: 1991). A Escola Profissional Feminina possuia características muito particulares no que diz respeito a educação das filhas de imigrantes e operários. Tais meninas raramente tinham acesso ao curso normal mais próximo da classe burguesa dita empobrecida e média. Cabe resaltar que a Escola Profissional Feminina de São Paulo não possuía o mesmo caráter assistencial do Seminário da Glória que era voltado a profissionalização de meninas orfãs e abandonadas.

A escolha das artes aplicadas à industria deveu-se principalmente ao crescente interesse político-econômico dos democratas liberais que perduram por toda primeira República, e tiveram grande repercussão em São Paulo devido ao forte impulso industrial 
proporcionado pelo grande acumulo de capital proveniente das exportações de café.(Cunha: 2000b:15)

Sobre este assunto Ana Mae Barbosa (1978), lembra a importância das contribuições liberais e positivistas para o ensino do desenho e aponta a influência de Rui Barbosa e de André Rebouças para a divulgação do trabalho desenvolvido por Walter Smith. Também faz referência à grande influência das Exposições Internacionais e aos resultados apresentados.

Rui Barbosa foi um grande entusiasta em relação ao ensino do Desenho, e destacou a necessidade de se preparar as classes menos favorecidas para o trabalho e para o engrandecimento da nação (1948: 239).

É possível observar a influência dos pareceres elaborados em 1883, por Rui Barbosa, sobre essa modalidade de ensino nos Annuarios do Ensino do Estado de São Paulo durante o período de 1909 a 1922. Assumindo o ensino do Desenho a forma de fomentador do gosto pelo trabalho as crianças nos cursos primários. A partir dos relatórios apresentados a Secretaria de Instrução Pública essa proposta liberal também era empregada ao ensino de trabalhos manual.

Sob a influência positivista tais atividades eram recomendadas como forma de desenvolver a disciplina, a destreza e as habilidades manuais. Essa ideologia foi também um grande fator que pretendeu concorrer para a divulgação do ensino do desenho, principalmente o geométrico, para a formação do operário racional, disciplinado e asseado.

No Livro de Recortes de Jornal elaborado pela direção da Escola Profissional Feminina, é possível constatar nas notas veiculadas nos jornais da época, que a disciplina se apresentava como uma grande qualidade instituída pela escola as alunas. A figura de uma colméia empregada na época aparece como uma alusão, à rígida disciplina imposta às futuras operárias.

Ao analisar a criação da Escola Profissional Feminina de São Paulo temos subsidios à compreensão de uma concepção de ensino de arte tecnicista que atuou como agente profissionalizador feminino, de acordo com os interesses políticos econômicos de sua época.

Sob esse aspecto o estudo e a revisão da história de uma prática de ensino em arte repleta de singularidades pode subsidiar a compreensão de sua fundamentação teórica e das origens de algumas práticas pedagógicas. Essa revisão do ensino de arte é de grande importância, pois as práticas, teorias e concepções pedagógicas são frutos de seu tempo e suas influências atuam sobre os educadores de forma direta ou indireta e muitas vezes distorcida, propiciando uma reflexão sobre as origens das práticas e dos preconceitos pedagógicos ainda existentes no campo do ensino de arte.

O trabalho se caracteriza como uma análise da bibliografia levantada para o entendimento do tema proposto. Como fontes de pesquisa foram utilizados pareceres e anuários apresentados pela Secretaria de Instrução Pública e outros documentos oficiais da própria Escola Profissional Feminina de São Paulo. Por meio do discurso de seus relatores tornou-se possível investigar a ideologia contida nas concepções de ensino da arte e buscou-se também conceituar, dentro do período compreendido entre 1910 a 1940, o que significava a profissionalização feminina.

\section{Fontes}

Secretaria de Instrução Pública. Annuario do Ensino do Estado de São Paulo. São Paulo: 1911a 1922 
Escola Profissional Feminina. Acta de Inauguração Official da Escola Profissional Feminina. São Paulo. São Paulo: 1911.

Escola Profissional Feminina. Livro de Recortes de Jornal. São Paulo, 1912/1966.

SILVEIRA, Horácio A. Relatório da Escola Profissional Feminina. São Paulo, 1922

FREITAS, Maria Vitorino de. Tecnologia. Artes e Ofícios Femininos. 2ª São Paulo, 1954

\section{Referência Bibliográfica}

BARBOSA, Ana Mae T. B. Arte-educação no Brasil das origens ao modernismo. São Paulo: Perspectiva, 1978.

BARBOSA, Ana Mae T. B. Recorte e Colagem. Influencias de J. Dewey no ensino da arte no Brasil. São Paulo: Cortez, 1982.

BARBOSA, Rui. “O Desenho e a Arte Industrial”. Obras Completas de Rui Barbosa, V.9. Rio de Janeiro, 1948

BERNARDES, Maria T. Caiuby Crescenti. Mulheres educadas. Rio de Janeiro do século XIX, (1840 1890). São Paulo, 1983 (Dissertação de Doutorado - USP).

CUNHA, Luiz A. O ensino de ofícios artesanais e manufatureiros no Brasil escravocrata. São Paulo: UNESP, 2000a.

CUNHA, Luiz A. O ensino de ofícios nos primórdios da industrialização. São Paulo: UNESP, 2000b.

GONZAGA, Aprigio. "Finalidade do Ensino Profissional Feminino". Annuario do Ensino do Estado de São Paulo - 1920-1921.

LEITE, Míriam Moreira (org.). A condição da mulher no Rio de Janeiro no século XIX: Antologia de textos de viajantes estrangeiros. São Paulo: Hucitec, 1984.

MANUEL, Ivan Aparecido, Igreja e educação feminina. (1859-1919): Uma face do conservadorismo. São Paulo: UNESP, 1996.

MORAES, Carmen S. V. e ALVES, Júlia F. (org). Escolas Profissionais Públicas do Estado de São Paulo. Uma História de Imagens. São Paulo, Imprensa Oficial do Estado, 2002.

NADAI, Elza. "Educação de elite e a profissionalização da mulher brasileira na primeira República: discriminação ou emancipação?” in: Revista da Faculdade de Educação, São Paulo: USP, 1991.

NEEDEL, Jefrey D. Belle Époque Tropical. Sociedade e cultura de elite no Rio de Janeiro na virada do século. Trad. Celso Nogueira. São Paulo: Companhia das Letras, 1997.

NAGLE, Jorge. Educação e sociedade na Primeira Republica. 2a . Rio de Janeiro: DP\&A, 2001. 
OLIVEIRA, Sueli Teresa de, Uma colméia gigantesca: Escola Profissional Feminina de São Paulo. São Paulo, 1992 (Dissertação de Mestrado - PUC).

PEIXOTO, Afrânio. Educação da mulher. São Paulo: Nacional, 1936.

REIS, Maria Cândida Delgado. Tessitura de destinos. (Mulher e educação: São Paulo, 1910/20/30). São Paulo, 1991 (Dissertação de Mestrado - PUC).

SILVEIRA, Horácio A. Escola Normal Feminina de Artes e Officios; (São Paulo). Histórico e organização actual. São Paulo: Limitada, 1931. 